\title{
Matemática Inclusiva: Ensinando Matrizes a Deficientes Visuais
}

\author{
Inclusive Mathematics: Teaching Matrices For Visually Impaired
}

Tiago Stefanelo e Silva ${ }^{1}$ e João Roberto Lazzarin ${ }^{2}$

${ }^{1}$ Mestre, IFF, Santo Augusto, Brasil

tiago.silva@iffarroupilha.edu.br

${ }^{2}$ Doutor, Departamento de Matemática, UFSM, Santa Maria, Brasil

lazzarin@smail.ufsm.br

\begin{abstract}
Resumo
Nos últimos anos, a inclusão de alunos com deficiência no sistema educacional brasileiro vem sendo amplamente discutida. Entre as dificuldades desse processo, podem ser citados a estrutura inadequada das escolas e o despreparo dos professores. Nesse sentido, esforços individuais dos docentes são necessários na busca por estratégias pedagógicas que minimizem tais dificuldades. Neste artigo, temos por objetivo apresentar um estudo de caso em que o conteúdo de matrizes do Ensino Médio foi trabalhado com um aluno com deficiência visual total. Para este trabalho, fizemos uso de um modelo de material concreto de baixo custo, que foi desenvolvido em conjunto com o Núcleo de Apoio às Pessoas com Necessidades Especiais (NAPNE) do Instituto Federal Farroupilha, campus Santo Augusto - RS. Serão apresentadas algumas técnicas diferenciadas usadas pelo aluno no decorrer do processo de aprendizagem e abordadas algumas posturas que o professor pode adotar para favorecer esse processo.
\end{abstract}

Palavras-chave: Inclusão de deficientes visuais; Matemática inclusiva; Matrizes

\section{Abstract}

In recent years, the inclusion of disabled in the Brazilian educational system has been widely discussed. Among the difficulties of this process can be cited the inadequate structure of schools and the lack of preparation of teachers. In this sense, individual efforts of teachers are needed in the search for educational strategies to minimize such difficulties. This article aims at presenting a case study in the School matrices content was worked with a visually impaired student. For this work, we used a lower cost concrete material model developed jointly with the Support Center to Persons with Special Needs of the Farroupilha Federal Institute (NAPNE), Campus Santo Augusto - RS. We present some different techniques used by the student during the learning process and discuss some positions that the teacher may adopt to encourage this process.

Keywords: Visually impaired inclusion; Inclusive mathematics; Matrices 


\section{Introdução}

Nos últimos anos, a inclusão de pessoas com deficiência vem sendo amplamente discutida, porém, ainda são poucas as alternativas para um processo que seja realmente inclusivo, pois ainda esbarramos em muitas dificuldades tanto estruturais quanto formativas. Sabemos que o processo de inclusão enfrentado nas escolas não é uma tarefa simples, é preciso que o professor esteja preparado, entenda o tipo de deficiência com a qual vai trabalhar e busque alternativas para que possa desenvolver da melhor forma possível o processo.

O presente trabalho tem como objetivo principal relatar um processo de ensino-aprendizagem, procurando introduzir o conceito de matrizes e suas operações elementares para um aluno com deficiência visual total. Em (FERREIRA, 2006) e (MEIRA, 2008) existem descrições e aplicações de ferramentas sofisticadas que exigem material tecnológico avançando que podem ajudar nessa tarefa, tais como, o NonVisual Desktop Access (NVDA, 2016) e o MathML (2016) permitem uma interação do aluno cego com vários conceitos matemáticos. Porém, além do custo de implantação, essa interação é não tátil e baseada na audição, o que pode trazer dificuldades no aprendizado aos alunos iniciantes ou não ouvintes. Nossa proposta nesse trabalho é a utilização de material concreto simples, que pode ser confeccionado sem grandes recursos financeiros ou tecnológicos, nos moldes do Multiplano (FERRONATO, 2002), do Soroban e do Cubaritmo (bem descritos em (FERNANDES, 2006)), e que ao mesmo tempo produz efeito didático bastante significativo.

Este tema foi objeto de estudo de dissertação, desenvolvido no Programa de Mestrado Profissional em Matemática em Rede Nacional (PROFMAT), na Universidade Federal de Santa Maria - RS (SILVA, 2015). Nesse trabalho, nossa primeira seção é dedicada a um breve relato das políticas inclusivas brasileiras, destacando especialmente as que dizem respeito ao ensino de matemática para pessoas com deficiência visual. Na Seção 2, relatamos nossas aulas ante o aluno, iniciando com a confecção do material didático e expondo passo a passo o uso do material à medida que introduzíamos os conceitos de matrizes e as operações básicas envolvidas neste conteúdo obrigatório do ensino médio. Finalizamos o artigo com uma seção com nossas impressões sobre o trabalho realizado, fornecendo algumas diretrizes que o professor pode tomar ante o desafio de ensinar matemática a um aluno com deficiência visual.

\section{Políticas de educação inclusiva}

No Brasil, foram criadas leis que dão sustentação à política de educação especial, buscando a aceitação de Pessoas com necessidades especiais na sociedade. Esse processo começa pela integração dos mesmos nas escolas de ensino regular para que possam conviver em um ambiente de pessoas ditas "normais" e, assim, diminuir as barreiras do preconceito. A principal lei brasileira relacionada ao assunto é a Lei Brasileira de Inclusão da Pessoa com Deficiência, também conhecida como Estatuto da Pessoa com Deficiência (BRASIL, 2015), que veio ratificar, ampliar ou substituir várias outras Leis anteriores que de alguma forma asseguravam o direito a inclusão e foram elaboradas entre 1988 e 2001, sendo algumas delas: a Constituição Federal, o Estatuto da Criança e do Adolescente, a Lei de Diretrizes e Bases da Educação e o Plano Nacional de Educação. Também foram criados decretos, portarias, resoluções e pareceres, documentos estes, que buscam garantir os direitos à educação regular da pessoa com deficiência e assim, facilitar a sua inclusão social como um todo.

Todas essas leis dão amparo e suporte a matricula compulsória do aluno com deficiência em escolas da rede regular de ensino, e a partir dessas políticas públicas, o número de matrículas de alunos com necessidades especiais em turmas regulares vem crescendo nos últimos anos. Esse crescimento pode ser observado, na Figura 1 abaixo, com dados do Censo de 2015, realizado pelo Ministério da Educação (BRASIL, 2016):

Com base nesses dados, percebe-se a necessidade de um ambiente escolar inclusivo, para isso, as leis devem ser levadas a sério e cumpridas. O Estado, em suas diferentes esferas, precisa ter consciência da realidade das escolas e buscar formas de enfrentamento desse desafio.

Embora todos os documentos legais sobre Educação elaborados após a Constituição Federal de 1988 o direito ao atendimento educacional especializado, preferencialmente na rede regular de ensino, para aqueles hoje denominados alunos com necessidades educacionais especiais, sabe-se que não se viabiliza a referida prerrogativa sem que se garanta, enquanto responsabilidade do Estado, suportes humanos, físicos, materiais e outros. Isso implica, necessariamente, maior investimento financeiro e compromisso político com a educação brasileira, portanto, a figuração dessa área de política social como prioridade, de fato, do governo. (PRIETO, 2006).

Por outro lado, a comunidade escolar, num todo, (diretores, professores, alunos e funcionários), também deve buscar aceitar e se adaptar às mudanças. É preciso estar aberto a elas. Muitas vezes, faltam os recursos necessários para a inclusão e sobra só a boa vontade das pessoas que trabalham nas escolas e que lutam por ela. Não se pode transformar em utopia uma inclusão tão desejada, por isso, toda iniciativa nesta direção é bem vinda. 


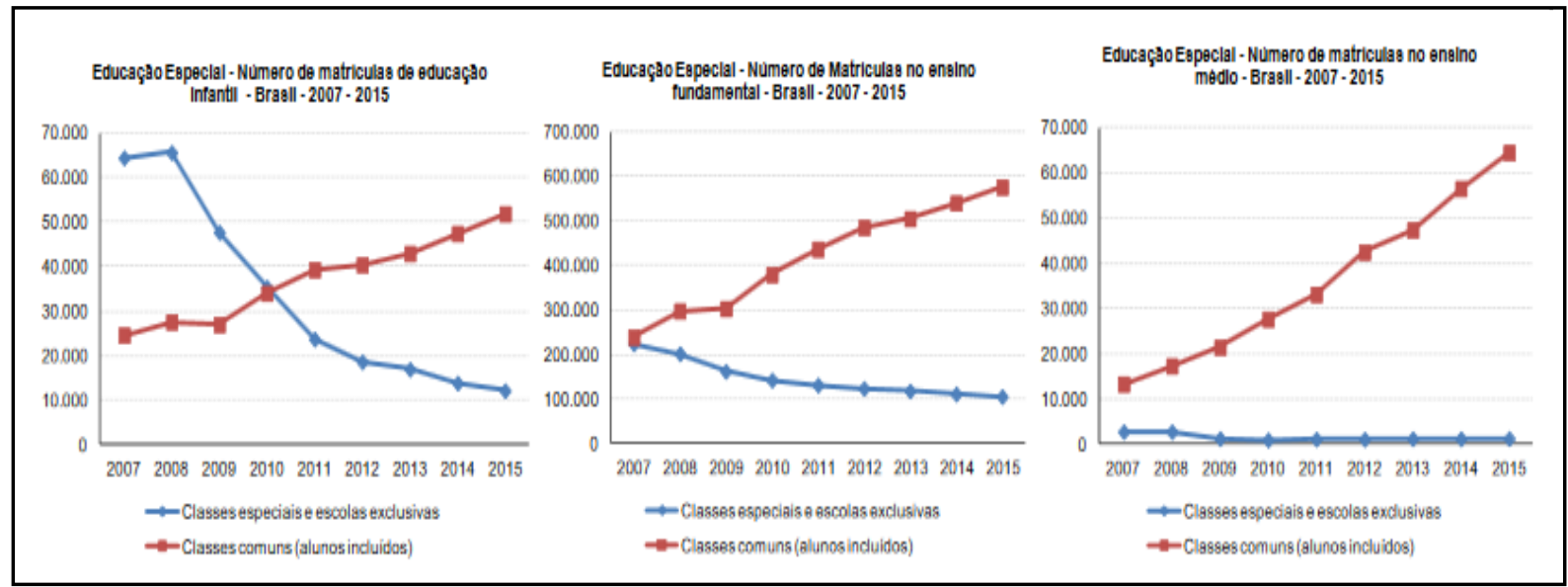

Figura 1 - Aumento de matrículas de alunos com algum tipo de necessidade especial entre os anos de $2007-2015$. Fonte: Instituto Nacional de Estudos e Pesquisas.

\section{A deficiência visual e a matemática}

Entre os muitos tipos de deficiência, a visual lança um grande desafio ao professor: Como trabalhar determinadas disciplinas, visto que cada vez mais os professores estão empregando recursos visuais para tornar as aulas mais atrativas? Assim, é preciso desenvolver estratégias para trabalhar de forma diferenciada com esse aluno, ou quando possível, com toda a turma, para que ele não se sinta excluído. Para Romagnolli:

“...a aceitação e flexibilidade do professor em relação à sua limitação é um dos principais fatores que afeta a inclusão do aluno com baixa visão. É necessário incluí-lo na sala de aula e no ambiente escolar, propiciar interação com seus colegas, promover sua socialização, resgatar sua autoestima e cidadania." (R0MAGNOLLI, 2008).

Dessa forma, surge certa urgência em desenvolver pesquisas, metodologias e capacitações para o professor nortear seu trabalho, criar um novo olhar sobre a educação inclusiva. No âmbito da Matemática não é diferente, podemos notar que os trabalhos práticos ou pesquisas teóricas ainda são bastante limitados. Os desafios são muitos, principalmente com a escassez de material para se trabalhar inclusivamente até mesmo os conceitos matemáticos mais básicos que envolvem conteúdos do Ensino Fundamental e Médio.

É preciso ter em mente que o deficiente visual não possui uma deficiência de caráter cognitivo, logo, ele é capaz de aprender, bastando apenas que lhe sejam oferecidas as condições adequadas. Além disso, é importante que o professor tenha conhecimento do tipo de deficiência visual com que vai trabalhar. Para que o professor desenvolva um trabalho consistente, ele deve levar em conta que o deficiente visual não tem as mesmas experiências sensoriais dos demais alunos.

O desenvolvimento cognitivo do deficiente visual está principalmente relacionado aos sentidos do tato e da audição, assim, para que o professor possa desempenhar um trabalho que resulte em uma educação realmente inclusiva é importante que ele esteja atento a esse fato. É preciso desenvolver estratégias para que o aluno com deficiência tenha as experiências sensoriais necessárias para que aprenda de forma consistente.

No campo da Matemática, temos um grande desafio a ser superado, poucas editoras trabalham com materiais específicos para o deficiente visual e a escassez de material ainda é uma realidade, logo, é preciso desenvolver métodos alternativos para que este aluno possa ser inserido de forma eficiente na comunidade escolar. É necessária a criatividade, criar formas simples, com baixo custo, e que surtam resultados nesta busca pela inclusão.

“Trabalhar Matemática com alunos deficientes visuais parece ser uma tarefa não muito fácil. Isso porque esses alunos precisam estar em contato direto com o que está sendo ensinado, ou seja, eles precisam literalmente "sentir" para poderem fazer suas abstrações. Não que os outros alunos não tenham essa necessidade, mas é que no caso dos deficientes visuais, o concreto é o principal meio de conhecimento das coisas que os cercam. Desse modo, ao professor cabe a responsabilidade de estar buscando estratégias concretas que possibilitam a compreensão de todos os alunos. " (ARAÚJO, 2005).

Um ponto importante para que o professor de Matemática tenha êxito no trabalho com o deficiente visual é o uso de comunicação bastante clara. Dessa forma, o aluno pode compreender o que está sendo sugerido pelo professor. Para Fernandes: 
“...a cegueira dos aprendizes os impede de imitar diretamente as estratégias e os gestos usados pelos seus parceiros, assim o emprego de estratégias e gestos similares são fruto dos diálogos que permitem que as informações recebidas sejam tratadas e processadas para auxiliarem na formulação de estratégias para solução dos problemas matemáticos propostos.

" (FERNANDES, 2007).

Assim, vemos a importância da clareza e da riqueza de detalhes que o professor deve atentar ao realizar o trabalho com o deficiente visual, em termos de comunicação oral. Como o deficiente visual não tem uma ideia global do que está sendo trabalhado, é preciso que a descrição do conceito ou exercício que esteja sendo apresentado seja enriquecida com o máximo de informações e que se atente para que essas informações sejam de fato relevantes.

Neste trabalho, procuramos desenvolver um método alternativo para o estudo de matrizes, deixando o rigor matemático de lado, optando por uma abordagem simples e prática, tentando abrir possibilidades para a que o aluno abstraia esse "sentir" matemático. Também procuramos trabalhar com materiais de fácil acesso e baixo custo, de modo a tornar essa experiência acessível a qualquer professor que esteja disposto a trabalhar com esse tipo específico de deficiência.

\section{Atividades desenvolvidas}

Esperamos que o leitor esteja familiarizado com as notações e operações básicas envolvendo matrizes. Por exemplo, uma matriz genérica de ordem $M x N$ é denotada frequentemente por onde o índice $i=1, \ldots, N$, indica sempre a posição linha e o índice $j=1, \ldots, M$, indica sempre a posição coluna do elemento $\mathrm{a}_{\mathrm{ij}}$ na matriz; estabelecemos também que $\left(a_{i j}\right)=\left(b_{i j}\right)$ se, e somente, se $a_{i j}=b_{i j}$ para cada i e cada j envolvido; que a soma entre duas matrizes de mesma ordem e multiplicação de uma matriz por um escalar e feita de forma pontual, ou seja, $\left(a_{i j}\right)+\left(b_{i j}\right)=\left(a_{i j}+b_{i j}\right)$ e $c .\left(a_{i j}\right)=\left(c . a_{i j}\right)$ para toda constante c, e $\left(a_{i j}\right)$, finalmente o produto entre duas matrizes que só está definido entre uma matriz de ordem $M x N$ e outra de ordem $N \times R$ resultando em uma matriz de ordem $M x R$, é dado por $\left(a_{i j}\right) \times\left(b_{i j}\right)=\left(a_{i 1} \cdot b_{1 j}+a_{i 2} \cdot b_{2 j}+\cdots+a_{i N} \cdot b_{N j}\right)$. Para maiores detalhes sugerimos os livros (BONJORNO, 2013) ou (DANTE, 2012). Para introduzir estes conceitos utilizamos material didático cuja matéria prima pode ser adquirida a baixíssimo custo em qualquer papelaria e que pode ser confeccionado sem maiores dificuldades, desde que se tenha acesso a uma máquina de escrever em Braille.

Necessitamos basicamente de:

- Uma placa de metal com aproximadamente; $60 \mathrm{~cm} \times 40 \mathrm{~cm}$

- Imãs de geladeira;

- Folhas de papel Braille ou adesivos para Braille;

- Máquina de escrever em Braille;

- Folhas de EVA (opcional para decorar e encobrir as bordas da placa).

Primeiramente, datilografamos números positivos e negativos, (letras, sinais e demais itens) que vamos utilizar no papel ou adesivo para Braille. Em seguida, fixamos este material nos imãs de geladeira e recortamos de maneira adequada e cuidadosa, uma vez que o manuseio acontece sobre a placa de metal (ver Figura 2).

No primeiro encontro, trabalhamos os conceitos iniciais de matrizes, sua definição e a localização de elementos utilizando linhas e colunas. Além disso, a partir de aplicações práticas, como tabuleiros de jogos de dama ou xadrez, exemplificamos o uso de matrizes. No nosso caso, relacionamos uma matriz a uma tabela do editor de tabelas "Microsoft Excel", uma vez que nosso aluno tem certa familiaridade com este programa que usa números para relacionar as linhas e letras para relacionar colunas de uma tabela.

Estabelecemos de modo concreto o que se define como sendo uma matriz genérica, (ver Figura 3), e com base nesta matriz particular, fazendo o aluno sentir cada subquadrado formando um grande retângulo, fixamos que cada subquadrado representa um elemento da matriz e que sua posição no retângulo é perfeitamente localizável através de dois índices. Foi possível explicar que o primeiro índice representa a linha de sua localização e o segundo representa a coluna em que esse subquadrado se encontra. A tradução dos termos aij para o Braille não é literal, por exemplo, a11 é traduzido como "a onze", $\mathrm{a}_{12}$ traduzido como "a doze", etc. Usamos esta notação com o objetivo único de minimizar o tamanho das pastilhas que representam cada elemento de uma matriz e com isso otimizar o uso do quadro, com várias matrizes concomitantes.

Nas duas aulas seguintes, trabalhamos a construção de matrizes cujos elementos são obtidos através de uma fórmula que depende exclusivamente de seus índices, dentre estas, os tipos clássicos de matrizes: matriz diagonal, matriz triangular, matriz nula, matriz identidade, etc. (Figura 4). Nestas aulas, merecem destaque as retomadas de conceitos de matemática básica, em que revisamos as regras de sinal na multiplicação. Com o material concreto, o aluno pôde assimilar de forma bem significativa os conceitos apresentados e estabelecer um procedimento por 


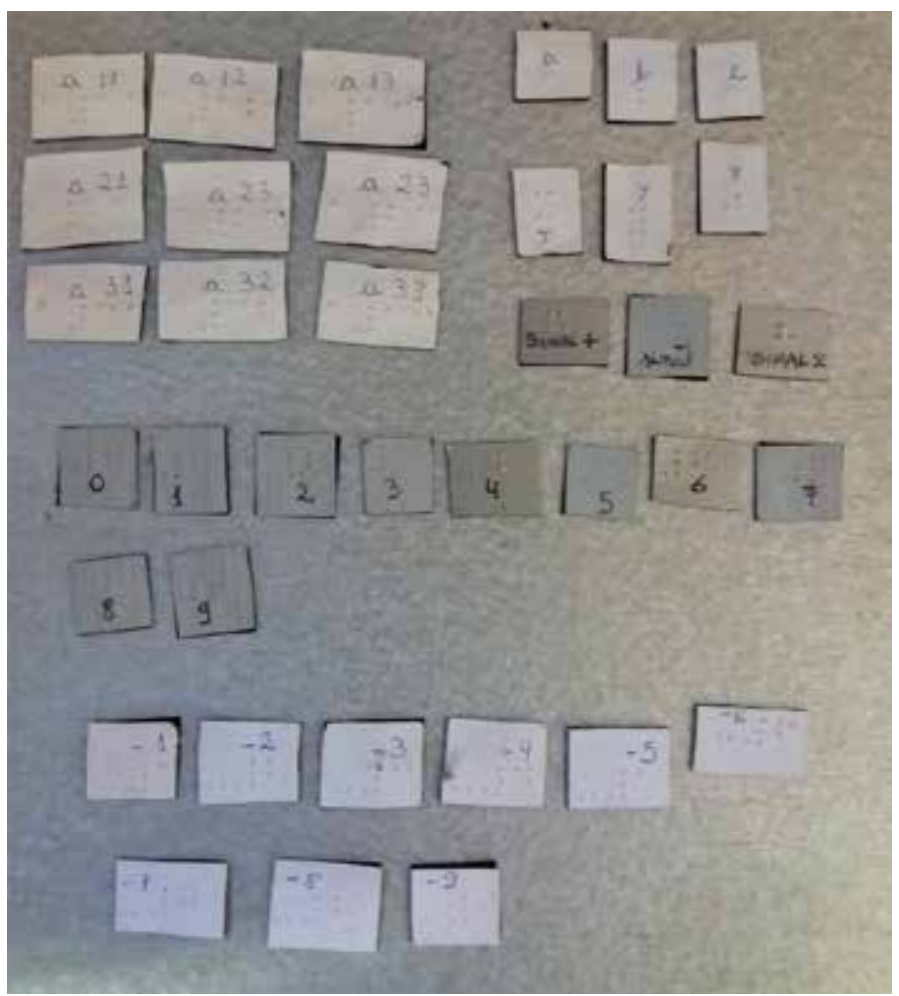

Figura 2 - Material concreto

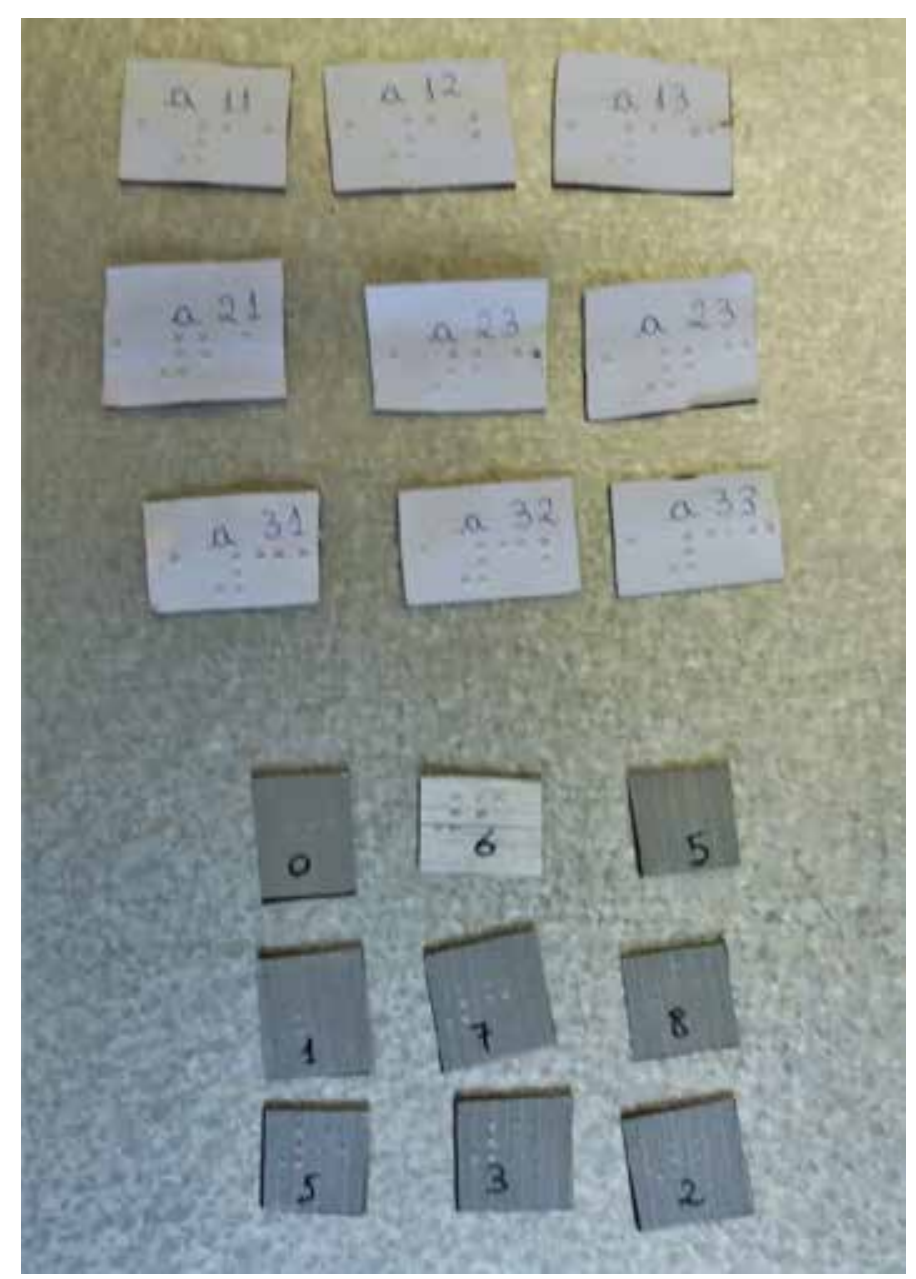

Figura 3 - Matriz genérica e exemplos de matrizes utilizadas nas atividades de localização de elementos 
ele adotado e que não foi induzido por nós: em todas as atividades de fixação de conteúdo, ele sempre partia da montagem da matriz genérica, estudava o posicionamento de cada elemento que seria utilizado em algum cálculo e a partir daí obtinha uma resolução da atividade proposta.

Nas aulas restantes foram trabalhadas operações básicas envolvendo matrizes: adição, subtração, multiplicação de matrizes por um número real e multiplicação de matrizes. Nessas aulas, sempre iniciamos com o algoritmo da operação, trabalhando com o material concreto, primeiramente relembrando o posicionamento de cada elemento da matriz para em seguida, considerada a noção de igualdade entre matrizes, efetuarmos as operações necessárias para obtenção dos resultados. Vale salientar que o nosso aluno tem uma grande facilidade de memorização e realiza grande parte dos cálculos mentalmente, o que facilita o trabalho nessa etapa, mas que em geral, alunos com dificuldade de memorização precisarão fazer algumas anotações parciais em separado.
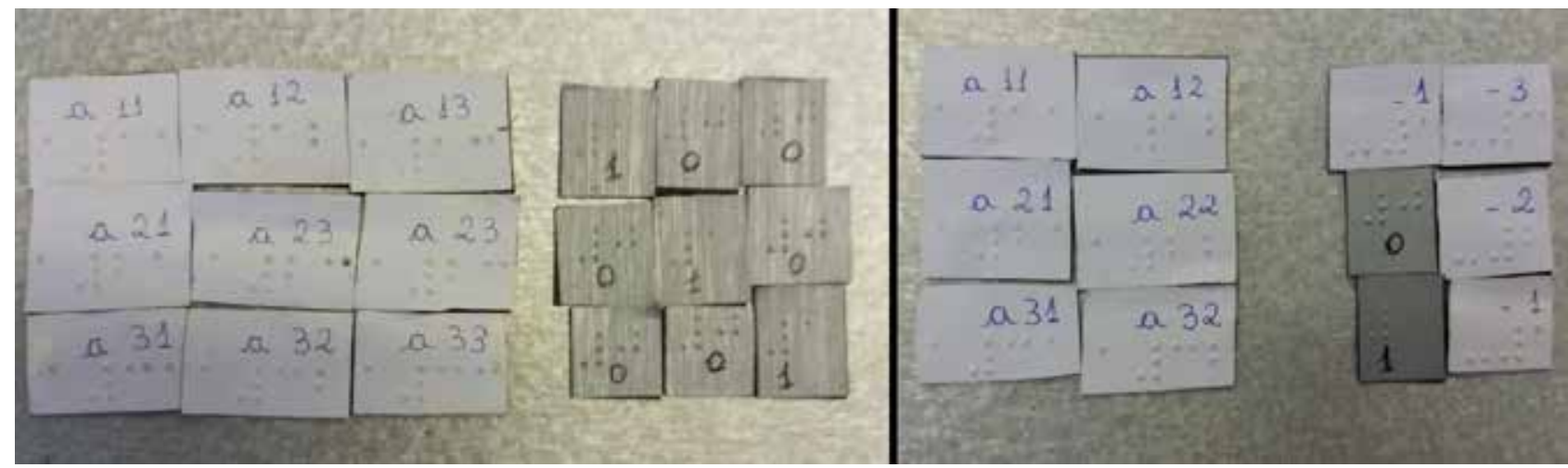

Figura 4 - Matrizes especiais obtidas a partir de fórmulas para aij em função dos índices i e j. Na primeira parte temos aij $=1$ se $\mathrm{i}=\mathrm{j}$ e aij $=0$ caso contrário. Na segunda parte temos aij $=\mathrm{i}-2 \mathrm{j}$ para todo $\mathrm{i}, \mathrm{j}$

Com relação às operações de adição e subtração, não foram encontradas dificuldades significativas. Realizamos alguns exercícios nos quais o aluno pôde proceder com a soma e a subtração de duas matrizes de ordem 2 . Esses exercícios envolveram a realização de cálculos e a colocação da matriz solução ao lado das matrizes montadas para as atividades sem nenhuma precisão de separá-las com o sinal de igualdade (Figura 5).

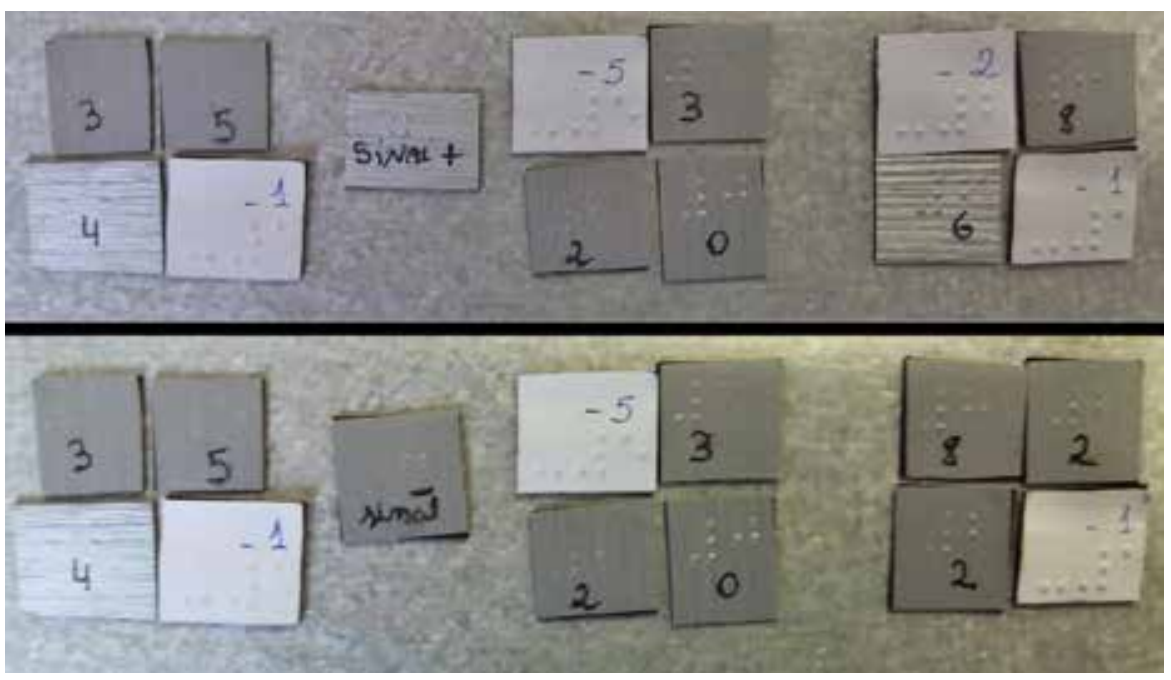

Figura 5 - Atividades de adição e subtração de matrizes realizadas pelo aluno

Na medida em que colocávamos mais ingredientes e operações, ficou clara a necessidade de revisarmos o conceito de igualdade entre matrizes, pois ali, o posicionamento de cada elemento da matriz resultante era descrito conforme o posicionamento dos elementos envolvidos na operação e este deveria ser devidamente anotado no mesmo quadro geral juntamente como todas as matrizes envolvidas, porém no lado oposto ao sinal de igualdade. Assim sendo, fez-se necessário a utilização de um símbolo de igualdade que abrangesse toda uma coluna para efetivamente separar as matrizes a serem efetuadas, da matriz resultante final. Concluímos, em conjunto com o aluno, que utilizar uma barra no formato de um retângulo estreito quase do tamanho da última coluna da última matriz envolvida nas contas, seria o mais conveniente para simbolizar a igualdade, pois utilizar um subquadrado 
com o símbolo de igualdade em Braille não seria suficiente para que ele sentisse em que lado estaria da igualdade (Figura 6 e Figura 7). Destacamos um exercício que continha equações com incógnitas (Figura 6), no qual o aluno preferiu montar a matriz com incógnitas e denota-la em separado, a resolver cada equação que surgia para cada par de índices ij. Executada essa etapa, igualou cada expressão a seus respectivos elementos do outro lado do travessão da igualdade e resolveu cada equação obtida, encontrando os valores das respectivas incógnitas e remontando a matriz solução.

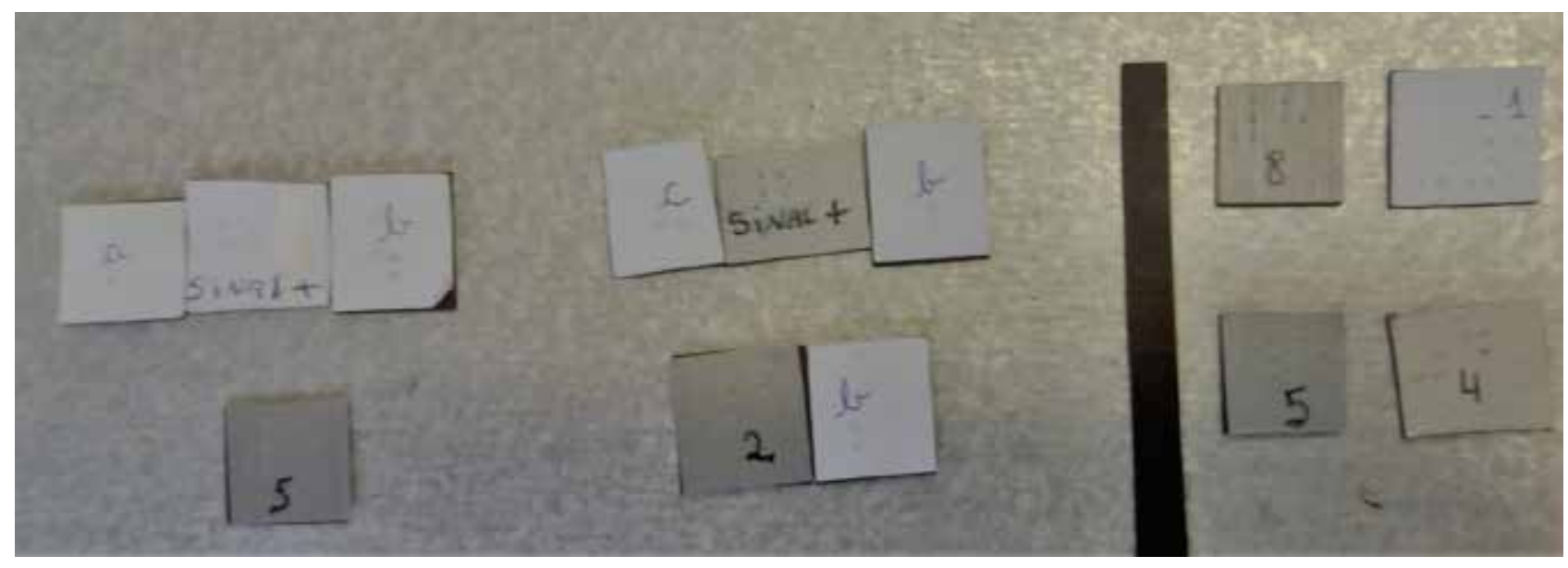

Figura 6 - Exercício sobre igualdade envolvendo incógnitas.

Por fim, merece destaque a estratégia de aprendizagem do aluno acerca da multiplicação entre matrizes: para encontrar, por exemplo, o elemento c12 da matriz resultante o aluno posicionou os dedos da mão esquerda sobre a linha 1 da matriz e os dedos da mão direita sobre a coluna 2 da matriz Dessa forma, os números que devem ser multiplicados ficaram sob os dedos correspondentes das suas mãos. Assim, tivemos uma experiência (representada na Figura 7) bastante positiva na resolução de exercícios que envolviam multiplicação de matrizes, método que pode ser aplicado a alunos iniciantes, mesmo aqueles sem deficiência visual, como modelo de fixação do método de multiplicação.

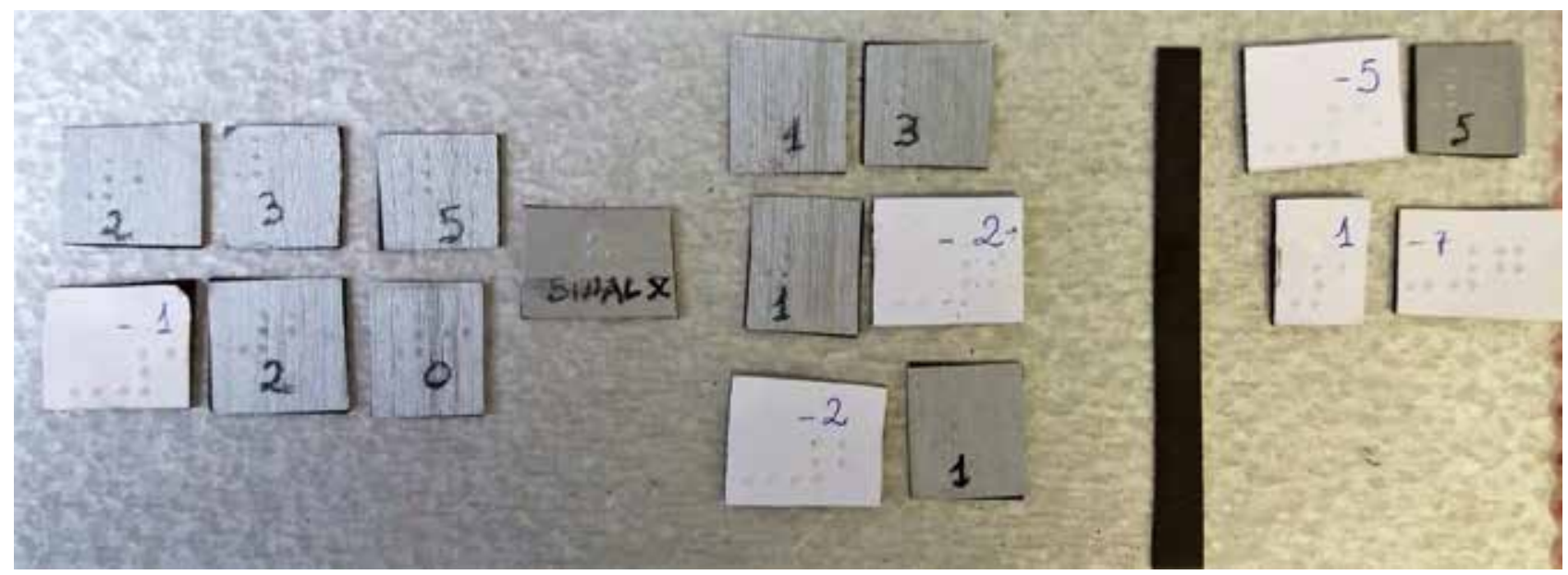

Figura 7 - Resolução de multiplicação de uma matriz 2x3 por uma 3x2

\section{Considerações finais}

O interesse por esse tema surgiu da atual necessidade de métodos alternativos para o ensino de pessoas com deficiência, visto que é crescente o aumento no número de matrículas desses alunos em turmas regulares nas escolas. O desafio de desenvolver atividades que possibilitassem o aprendizado dos principais conceitos envolvendo matrizes foi alcançado. Essas atividades oportunizaram a "visualização", através do tato, de como se organizam e se operam com matrizes. Nesse processo de aprendizagem, o material concreto foi de grande importância, uma 
vez que o aluno pôde tatear e movimentar, com certa facilidade, os objetos com os quais estava trabalhando. O desafio de buscar uma alternativa de baixo custo e de fácil mobilidade, na qual o aluno pudesse desenvolver certas atividades por conta própria, tateando, procurando elementos e construindo suas soluções, foi realizado a contento.

Nas aulas em que desenvolvemos as atividades com o material concreto, um fato importante a destacar foram as capacidades de memorização e de cálculos mentais apresentadas pelo aluno. Apesar de recorrer ao professor em alguns momentos, na maioria das vezes, ele conseguia resolver mentalmente grande parte das atividades. Se nos deparássemos com um aluno com maiores dificuldades de cálculo mental, talvez tivéssemos que introduzir mais lentamente os pormenores e repetir alguns pré-requisitos importantes para o desenvolvimento do conteúdo abordado.

Cabe aqui uma observação que não pode ser deixada de lado: o professor precisa, antes de tudo, conhecer as principais necessidades do aluno com que vai trabalhar. Por isso, tornam-se importantes algumas conversas informais com os alunos, uma vez que, por meio delas, podemos dirimir algumas dificuldades iniciais, que tanto o professor quanto o aluno possam vir a enfrentar durante o processo de ensino. Dessa forma, é também possível identificar as dificuldades de pré-requisitos mal adquiridos ou faltantes, tanto para a parte do conteúdo a ser trabalhado quanto para o domínio da linguagem Braille.

Dar a liberdade para que o aluno dê suas opiniões, contribui de forma significativa para uma melhora no desenvolvimento das atividades, pois talvez algo que para o professor seja mais bem visualizado esteticamente, para o aluno pode se tornar um transtorno. Um exemplo, que apareceu neste trabalho e que podemos citar é o de usar uma barra para simbolizar a igualdade entre expressões matemáticas. Apesar de uma "barra" não ser uma simbologia tradicionalmente usada para este fim, foi a alternativa que o aluno apontou como mais adequada para o senso tátil, uma vez que estas barras cobriam toda a extensão das matrizes, separando bem os fatores da resultante.

Uma postura interessante para o professor é se apresentar como um mediador, estando sempre presente nas etapas iniciais do processo de ensino, corrigindo possíveis erros em cada etapa. Um dos fatos que pudemos observar quando o aluno tentou utilizar o modelo sozinho foi o acúmulo de pequenos erros em cada etapa, erros que quase nunca eram do método em si, mas de efetuações aritméticas que precisavam ser memorizadas, tais como, por exemplo, regras de sinais em operações básicas. Tais erros são também comuns aos alunos ditos normais, porém, uma vez que o aluno deficiente visual não tem uma "visualização" global do exercício, ao cometer tais erros no desenvolvimento dos cálculos, a simples verificação do resultado final pode dificultar muito na localização do movimento incorreto, além de dificultar na capacidade de assimilação do processo como um todo.

Apesar das dificuldades encontradas, percebemos que é possível trabalhar com o aluno com deficiência de forma qualificada, para que este se sinta inserido de forma significativa no ambiente escolar. Podemos notar que ainda são poucas as pesquisas e atividades desenvolvidas nesse campo e que é preciso que se incentive a busca por novos métodos de ensino para esses alunos. Este trabalho foi realizado, buscando um método alternativo para se trabalhar um conteúdo específico do Ensino Médio, no entanto, ainda temos uma longa estrada a trilhar, visto que existe um amplo campo de disciplinas e conteúdos a serem abordados. O interessante é que os colegas professores possam se utilizar dessas ideias, modificando, melhorando e adaptando a sua realidade para que possamos ampliar o processo de inclusão e assim, torná-la em uma realidade de fato.

\section{Agradecimentos}

Agradecimentos a Capes e SBM pelo suporte financeiro com bolsas de estudos a um dos autores e aos avaliadores pelas boas sugestões na melhoria do texto.

\section{Referências}

ARAÚJO, M. O. A inclusão social e o ensino da matemática aos portadores de deficiências visuais no distrito federal. Disponível em: https://www.ucb.br/sites/100/103/TCC/22005/MarceloAraujo.pdf. Acesso em: 05 out. 2016.

BONJORNO, J. R.; GIOVANNI, J. R; GIOVANNI, J. R J. Matemática completa. São Paulo: FTD, 2013.

DANTE, L. R. Matemática: contexto e aplicações, São Paulo: Ática, v. 2, 2012.

BRASIL, Ministério da Educação e Cultura, Censo Escolar 2015: Notas Estatísticas, , Brasília, 2016. 
BRASIL, Lei Federal no 13.146 (Estatuto da Pessoa com Deficiência), Diário Oficial da União; Poder Executivo, 7 jul. 2015. Seção 1, Brasília, p.2-11, 2015.

FERNANDES, S. H. A. A.; HEALY, L. As concepções de alunos cegos para os conceitos de área e perímetro. In: Encontro Nacional de Educação Matemática, Belo Horizonte, p. 1124, 2007.

FERNANDES, C. T.... [et al.] A construção do conceito de número e o pré-soroban, Ministério da Educação, Secretaria de Educação Especial, Brasília, 2006.

FERREIRA, H.; FREITAS, D. Leitura de Fórmulas matemáticas para cegos e amblíopes: A aplicação AudioMath. IBERDISCAP'06, Vitória, 2006.

FERRONATO, R. A construção de instrumento de inclusão no ensino da matemática. Dissertação (Mestrado) Programa de Pós-Graduação em Engenharia de Produção, Universidade Federal de Santa Catarina, Florianópolis, 2002.

MathML, Editor de símbolos matemáticos para WEB, Disponível em: www.w3.org/Math. Acesso em 05 out. 2016.

NVDA, NonVisual Desktop Access. Disponível em: http://www.nvaccess.org . Acesso em 05 out. 2016.

MEIRA, J. N....[et al.]. Uma Ferramenta de Autoria de Materiais Instrucionais com Símbolos Matemáticos Acessíveis a Deficientes Visuais, In: XIX Simpósio Brasileiro de Informática na Educação, Fortaleza, 2008.

PRIETO, R. G. Políticas de melhoria da escola pública para todos: tensões atuais. Sessão Especial, Educação On-line, 2004. Disponível em: http://educacaoonline.pro.br/index.php?option=com_content\&view=article\& $\mathrm{id}=26$ :sessao-especial-politicas-de-melhoria-da-escola-publica-para-todos-tensoes-atuais\&catid=5:educacaoespecial\&Itemid=16. Acesso em: 05 out. 2016.

ROMAGNOLLI, G. Suely Eastwood; ROSS, P. R. Inclusão de aluno com Baixa Visão na rede pública de ensino: Orientação para professores, Programa de Desenvolvimento Educacional, Universidade Federal do Paraná, Curitiba, p. 21, 2008.

SILVA, T. S. Matemática inclusiva: ensinando matrizes a deficientes visuais, Dissertação de Mestrado, 2015. 